\title{
The Larvae of Two Scorpaenid Fishes, Sebastes wakiyai and $S$. iracundus
}

\author{
TOru SASAKI* \\ (Received June 22, 1976)
}

\begin{abstract}
The larvae collected from two species of mature females, Sebastes wakiyai and $S$. iracundus were examined. The size of these larvae when released were 2.9-3.2 mm TL in $S$. wakiyai and $4.2-4.9 \mathrm{~mm}$ TL in $S$. iracundus. It was easy to identify these larvae from the character of pigments and the size of the body. Comparing the present two species with three other species of rockfishes in Hokkaido already known, the larvae of each of these two species had specific pigment patterns which are considered most useful for identification.
\end{abstract}

Eighteen species of rockfishes inhabit off the coast of Hokkaido. ${ }^{1)}$ Most of them are commercially very important to fishermen and sport anglers. Although there is some provisional information on the development of larvae in southern species ${ }^{2-5)}$ and North American species, ${ }^{6-8)}$ the larvae in the northern species are almost unknown for they are ovoviviparous fish and there are few investigators.

In the present paper the author describes the morphology of the larvae of two species, Sebastes wakiyai and $S$. iracundus just before they were released, and also reveals the specific difference of the pigment useful for the identification of larvae.

\section{Material and Methods}

The rockfishes used in the present work were Sebastes wakiyai and S. iracundus. The female parents were collected off the coast of Esashi, in the Japan Sea, on July 6, 1975 for S. wakiyai (2 specimens, 207-220 mm TL), and off the coast of Kushiro on May 21, 1973 for $S$. iracundus ( 2 specimens, $321-361 \mathrm{~mm} \mathrm{TL}$ ). The larvae were artificially pressed out from the belly of the parents. They were fixed in $5 \%$ formalin. The pigment portions and the feature of the pigments followed DeLACY et al. ${ }^{\text {.) }}$

\section{Description of the Larvae}

1. S. wakiyai; 20 specimens, $2.9-3.2 \mathrm{~mm}$ TL, Fig. 1 .

Head length 4.5-5.9, head depth 5.2-7.7, preanal distance 2.2-3.1 in total length. Eye diameter 1.8-2.7, snout 5.0-6.4 in head length. Myomeres 26-27 in number.

Yolk sac almost absorbed. Body slender. Head smooth without any spine. Mouth comparatively large extending to below the middle part of the eye. Anus opening beneath the 8 th myomere. Posterior end of urochord straight. Pectoral fin small, fan-

* Laboratory of Marine Zoology, Faculty of Fisheries, Hokkaido University, Hakodate 041 Japan. (佐々木達：北海道大学水産学部水産動物学教室) 


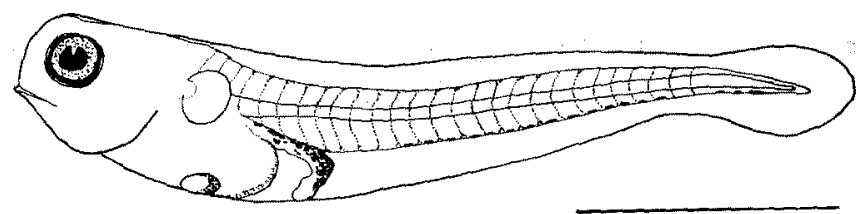

Fig. 1. Larva of Sebastes wakiyai, $3.20 \mathrm{~mm}$ TL, collected on July 6,1975 . Scale indicates $1 \mathrm{~mm}$.

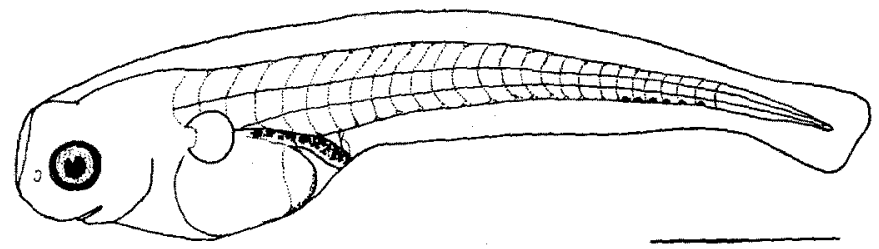

Fig. 2. Larva of Sebastes iracundus, $4.48 \mathrm{~mm} \mathrm{TL}$, collected on May 21, 1973. Scale indicates $1 \mathrm{~mm}$.

like in shape. Fin fold beginning from the top of the head and reaching ventral part through the dorsal and caudal parts. Hypural plate and pelvic fin not formed.

Small melanophores arranged on the hypural region, along the ventral margin of the posterior half of the body and on the dorsal part of the alimentary canal. 14-17 pigments along the ventral margin.

2. S. iracundus; 20 specimens, $4.2-4.9 \mathrm{~mm}$ TL, Fig. 2.

Head length 5.2-6.2, head depth 5.8 7.7, preanal distance 2.5-2.9 in total length. Eye diameter 2.4-3.1, snout 4.1-6.2 in head length. Myomeres very clear, 25-27 in number.

Yolk and oil globule remain in yolk sac. Body slender. Head smooth without any spine. Mouth situated below the eye, comparatively small. Anus opening beneath the 7-8th myomere. Pectoral fin small, fan-like in shape. Fin fold beginning from the top of the head. Hypural plate and pelvic fin not formed.

Several small melanophores arranged along the ventral margin of the posterior $1 / 4$ of body, but not extending forward; star-shaped melanophores along the dorsal part of the alimentary canal. 4-7 pigments along the ventral margin.

\section{Discussion}

The larvae examined here seemed to have reached the stage of development which is just before the release period, because they came out of the belly when the female parents were captured. The size of the larvae at this period is different from one species to another. According to SASAKI, ${ }^{9)}$ it is smaller in northern species than in southern ones. In the present study, the larvae are $2.9-3.2 \mathrm{~mm}$ in $S$. wakiyai and $4.2-4.9 \mathrm{~mm}$ in 
Table 1. Comparison among pigment patterns and birth sizes of 5 species of the rockfishes collected in Hokkaido. Items follow DELACY et al. ${ }^{7)}$ Species with asterisks are cited from SASAKI ${ }^{9)}$

\begin{tabular}{|c|c|c|c|c|c|}
\hline Items & S. steindachneri* & S. taczanowskii ${ }^{*}$ & S. schlegeli* & S. wakiyai & S. iracundus \\
\hline Ventral pigment row present & + & + & + & + & + \\
\hline Ventral row stops short of anus & + & + & + & + & + \\
\hline Ventral row multiple or irregular & + & - & - & - & $\rightarrow$ \\
\hline Dorsal pigment row present & + & + & + & - & - \\
\hline Dorsal row stops short of anus & + & + & + & - & - \\
\hline $\begin{array}{l}\text { Dorsal row multiple or irregular } \\
\text { Head or nape with at least }\end{array}$ & + & - & - & - & - \\
\hline some pigments & + & + & + & - & - \\
\hline Head with 2 to 5 melanophores & + & - & - & - & - \\
\hline $\begin{array}{l}\text { Head with more than } 5 \\
\text { melanophores }\end{array}$ & - & + & + & - & - \\
\hline Lower jaw with pigments & - & - & - & - & - \\
\hline $\begin{array}{l}\text { Hypural region with pigment } \\
\text { spot(s) }\end{array}$ & - & + & + & + & $=$ \\
\hline $\begin{array}{l}\text { Total length of larvae ap- } \\
\text { proximately at birth (mm) }\end{array}$ & $3.5-4.8$ & $4.4-5.4$ & $5.1-6.1$ & $2.9-3.2$ & $4.2-4.9$ \\
\hline
\end{tabular}

S. iracundus. Since the larval size in southern species is $6.9-7.0 \mathrm{~mm}$ in $S$. pachycephalus nigricans, ${ }^{2)}$ 6-7 mm in S. pachycephalus pachycephalus ${ }^{4)}$ and 7.25-7.5 $\mathrm{mm}$ in S. oblongus, ${ }^{3}{ }^{3}$ it was found that the present larvae were also smaller than those of the southern species.

When the pigment pattern is compared between $S$. wakiyai and $S$. iracundus, the pigments along the ventral margin are different in number and in position. The former species is distinguished from the latter in having a larger number of pigments on the hypural region.

SASAKI $^{9}$ ) described eleven characters of the pigment pattern of three species of rockfishes from off the coast of Hokkaido. The pigment pattern is summarized for five species of rockfishes including the two species examined here (Table 1). The present larvae are distinguished from the other three species in having no pigments along the dorsal margin of the body. In $S$. iracundus, it is easily distinguished from the other four species by the appearance of the pigment only on the ventral margin and no pigments on any other portions.

$S$. wakiyai and $S$. taczanowskii belong to the subgenus Mebarus. ${ }^{10}$ Although their external feature at the adult stage are very much alike, these larval forms can be identified by the pigment pattern and the size at the release period (Table 1).

Some North American rockfishes have the pigments on the upper jaw. ${ }^{6,7)}$ On the other hand, in the five species from off the coast of Hokkaido, there are no pigments on the upper jaw. Since these two groups belong to the same genus, Sebastes actually, this difference may be caused by the difference in the developmental stage at the released period from the parent. Moreover, it is suggested that the two groups might belong to a separate genus. 
The larvae of each species are characterized by a specific pigment pattern. The author concludes that the pigment pattern is very useful for the identification of the larvae in these species.

\section{Acknowledgment}

I thank Professor Takao Igarashi of the Laboratory of Marine Zoology, Hokkaido University, for his guidance and Dr. Kunio Amaoka of the same University for his advice. I am also indebted to Mr. Koji Abe of the Hokkaido Fishery Experimental Station in Kushiro and Mr. Mitsugu Toyoshima of the same University for supplying me with the specimens.

\section{References}

1) T. UENo: Hokusuishi-Geppo, 22, 1-28 (1965).

2) S. Fujrta: Japan. J. Ichthyol, 6, 91-93 (1957).

3) S. Funtra: This Bull., 24, 475-479 (1958).

4) T. Shiokawa and H. Tsukahara: Rec. Oceanogr. Wks. Jap., 5, 123-127 (1961).

5) H. Tsukahara: ibid., 6, 49 -55 (1962).

6) R.W. Morris: Calif. Fish Game, 42, 149-153 (1956).

7) A. C. DeLaCY, C. R. Hitz and R. L. Dryfoos: Wash. Dep. Fish. Res. Pap., 2, 51-67 (1964).

8) H. G. Moser: Copeia, 1967, 773-797 (1967).

9) T. SASAKI: Bull. Fac, Fish. Hokkaido Univ., 25, 169-173 (1974).

10) K. Matsubara: in "Fish Morphology and Hierarchy" (ed. by K. Matsubara), Part 2, IshizakiShoten, Tokyo, 1955, pp. 1071-1078. 